influenza surveillance in military barracks in Ghana, 2011. BMC Public Health. 2012;12:957. http://dx.doi.org/10.1186/14712458-12-957

5. Agbenohevi PG, Odoom JK, Bel-Nono S, Nyarko EO, Alhassan M, Rodgers $\mathrm{D}$, et al. Biosecurity measures to reduce influenza infections in military barracks in Ghana. BMC Res Notes. 2015;8:14. http://dx.doi.org/10.1186/s13104-014-0956-0

6. Monne I, Meseko C, Joannis T, Shittu I, Ahmed M, Tassoni L, et al. Highly pathogenic avian influenza A (H5N1) virus in poultry, Nigeria, 2015. Emerg Infect Dis. 2015;21:1275-7. http://dx.doi.org/10.3201/eid2107.150421

7. World Organisation for Animal Health. Update on highly pathogenic avian influenza in animals (type $\mathrm{H} 5$ and $\mathrm{H} 7$ ). Last updated Aug 8 [cited 2016 Feb 5]. http://www.oie.int/animalhealth-in-the-world/update-on-avian-influenza/2016/

8. Horimoto T, Kawaoka Y. Reverse genetics provides direct evidence for a correlation of hemagglutinin cleavability and virulence of an avian influenza A virus. J Virol. 1994;68:3120-8.

9. Subbarao EK, London W, Murphy BR. A single amino acid in the PB2 gene of influenza A virus is a determinant of host range. J Virol. 1993;67:1761-4.

10. Gabriel G, Dauber B, Wolff T, Planz O, Klenk H-D, Stech J. The viral polymerase mediates adaptation of an avian influenza virus to a mammalian host. Proc Natl Acad Sci U S A. 2005;102:18590-5. http://dx.doi.org/10.1073/pnas.0507415102

Address for correspondence: Gülsah Gabriel, Heinrich-Pette-Institute, Leibniz Institute for Experimental Virology, Martinistr 52, Hamburg 20251 Germany; email: guelsah.gabriel@hpi.uni-hamburg.de

\title{
Hepatitis E Virus in Yellow Cattle, Shandong, Eastern China
}

\section{Bingyu Yan, ${ }^{1}$ Li Zhang, ${ }^{1}$ Lianfeng Gong, Jingjing Lv, Yi Feng, Jiaye Liu, Lizhi Song, Qing Xu, Mei Jiang, ${ }^{1}$ Aiqiang $X u$}

Author affiliations: Shandong University, Jinan, China (B. Yan, L. Zhang, J. Lv, Y. Feng, J. Liu, L. Song, Q. Xu, A. Xu); Shandong Center for Disease Control and Prevention, Jinan (B. Yan, L. Zhang, J. Lv, Y. Feng, J. Liu, L. Song, Q. Xu, A. Xu); Yantai Center for Disease Control and Prevention, Yantai, China (L. Gong, M. Jiang)

DOI: http://dx.doi.org/10.3201/eid2212.160641

To the Editor: Hepatitis E, caused by hepatitis E virus (HEV), is recognized as a zoonosis (1). HEV has been identified in a wide range of animals, and swine is the primary reservoir (2). In cattle, HEV strains have been recently described in yak (3), Holstein cows and their milk (4), and dairy cows in Xinjiang Province, China (5), but not in other cattle. Yellow cattle (Bos taurus), the predominant breed $(\approx 80 \%)$ in China ( 6 ), widely distributed over the country, and commonly used for meat and milk production or as a draft animal, could act as a potential HEV reservoir. The objective of this study was to determine whether HEV strains are circulating among yellow cattle in Shandong Province of eastern China.

During April-November 2011, a total of 842 blood samples from yellow cattle of local breeds were collected monthly as part of a severe fever with thrombocytopenia syndrome virus study. These samples were obtained from Laizhou and Penglai Counties ( $\approx 100 \mathrm{~km}$ apart) of Yantai Prefecture in Shandong Province.

Because the prevalent seasons for human HEV in this region were winter and spring, 254 samples (Laizhou $=131$; Penglai $=123$ ) collected only in April and November were selected for detection of HEV. All 254 cattle appeared to be healthy. Sixteen were $<1$ year of age, 108 were $1-3$ years of age, and 130 were $>3$ years of age. The cattle came from 20 villages (10 villages per county) and were raised by the local peasants, who owned an average of 2 cattle (range $1-8$ ). The animals were bred mainly to produce meat and seldom to produce milk.

Additional serum samples from domestic sheep, dogs, and chickens were also collected in this region simultaneously (online Technical Appendix Table 1, http://wwwnc. cdc.gov/EID/article/22/12/16-0641-Techapp1.pdf). All blood samples were centrifuged, and the separated serum was stored at $-70^{\circ} \mathrm{C}$ until use. The protocol for animal sampling was approved by the Animal Care Committee of the Chinese Center for Disease Control and Prevention.

We tested serum samples for total antibodies against HEV by using a double-antigen sandwich ELISA kit (Wantai Biological, Beijing, China) that uses a recombinant peptide of HEV open reading frame 2 (aa 394-606) from the virus as the antigen (7). Overall, the proportion seropositive for antibodies against HEV in yellow cattle was $47 \%(120 / 254 ; 95 \%$ CI $41 \%-54 \%)$, in line with the $28.2 \%$ positivity ratio previously reported in cattle from 26 provinces of China (8), suggesting that a high proportion of yellow cattle were exposed to HEV in this region. The proportions seropositive among sheep, dogs, and chickens were $32 \%(70 / 222), 41 \%(80 / 194)$, and $8 \%(41 / 484)$, respectively (online Technical Appendix Table 1).

We used nested reverse transcription PCR to amplify $644 \mathrm{nt}$ within HEV open reading frame 2 region, as described previously (9). We detected HEV RNA in 8 of 254 cattle samples; the overall proportion seropositive was $3 \%$. Positive yellow cattle included one $<1$ year of age, three $1-3$ years of age, and four $>3$ years of age. The 8 sequences obtained in this study (GenBank accession nos. KU904271, KU904273, KU904274, KU904278-KU904282) were subjected to phylogenetic analysis along with reference sequences for subtyping (10).

${ }^{1}$ These authors contributed equally to this article. 
Using MEGA 7.0 software (http://www.megasoftware. net) with the maximum-likelihood algorithm and a bootstrap of 1,000 replicates, we constructed a phylogenetic tree (online Technical Appendix Figure). All 8 sequences clustered within subtype $4 \mathrm{~d}$ of HEV. The sequences were similar to each other $(95.5 \%-99.8 \%$ similarity in nucleotide sequence) and similar to sequences reported for other cattle (83.3\%-85.3\%; online Technical Appendix Figure). Moreover, these sequences shared $96.1 \%-96.6 \%$ similarity with a human HEV strain (GenBank accession no. KC163335) from the Yantai Prefecture in 2012 and $95.7 \%-97.9 \%$ similarity with a swine strain (GenBank accession no. KF176351) isolated in Shandong Province the same year.

Our data strongly indicate that HEV infection occurs in yellow cattle and that they could also play a role as a reservoir of HEV. Because these animals serve mainly as a source of food, consumption of undercooked meat from yellow cattle, similar to pork, might also contribute to the transmission of HEV to humans. Additionally, we also detected HEV RNA in 8 of 70 sheep (online Technical Appendix Table 2). Eight sequences from yellow cattle had 95.1\%-99.8\% nt homology with 8 sheep-derived HEV strains, possibly because mixed raising of domestic livestock is popular in this region. Our finding of high sequence similarity between yellow cattle, sheep, swine, and human populations suggests a complicated interspecies transmission of HEV occurred in this province. Further studies are required to evaluate the contribution of the yellow cattle reservoir to human HEV infection.

\section{Acknowledgments}

We thank our colleagues at the China $\mathrm{CDC}$ at the prefectural and county level for sample collection in this study.

This study was supported by a grant from Taishan Scholar Program of Shandong Province (No. ts201511105) and a grant from the Shandong Medical Health Science and Technology Development Program (2015ws0042).

\section{References}

1. Kamar N, Bendall R, Legrand-Abravanel F, Xia NS, Ijaz S, Izopet J, et al. Hepatitis E. Lancet. 2012;379:2477-88. http://dx.doi.org/10.1016/S0140-6736(11)61849-7

2. Pérez-Gracia MT, García M, Suay B, Mateos-Lindemann ML. Current knowledge on hepatitis E. J Clin Transl Hepatol. 2015;3:117-26. http://dx.doi.org/10.14218/JCTH.2015.00009

3. Xu F, Pan Y, Baloch AR, Tian L, Wang M, Na W, et al. Hepatitis E virus genotype 4 in yak, northwestern China. Emerg Infect Dis. 2014;20:2182-4. http://dx.doi.org/10.3201/eid2012.131599

4. Huang F, Li Y, Yu W, Jing S, Wang J, Long F, et al. Excretion of infectious hepatitis $E$ virus into milk in cows imposes high risks of zoonosis. Hepatology. 2016;64:350-9. http://dx.doi.org/10.1002/ hep. 28668

5. Hu GD, Ma X. Detection and sequences analysis of bovine hepatitis E virus RNA in Xinjiang autonomous region [in Chinese]. Bing Du Xue Bao. 2010;26:27-32.
6. Li K, Zhang Y, Mao Y, Cornforth D, Dong P, Wang R, et al. Effect of very fast chilling and aging time on ultra-structure and meat quality characteristics of Chinese yellow cattle $M$. longissimus lumborum. Meat Sci. 2012;92:795-804. http://dx.doi.org/10.1016/j. meatsci.2012.07.003

7. Wang YC, Zhang HY, Xia NS, Peng G, Lan HY, Zhuang H, et al. Prevalence, isolation, and partial sequence analysis of hepatitis E virus from domestic animals in China. J Med Virol. 2002;67:51621. http://dx.doi.org/10.1002/jmv.10131

8. Geng Y, Wang C, Zhao C, Yu X, Harrison TJ, Tian K, et al. Serological prevalence of hepatitis $\mathrm{E}$ virus in domestic animals and diversity of genotype 4 hepatitis $\mathrm{E}$ virus in China. Vector Borne Zoonotic Dis. 2010;10:765-70. http://dx.doi.org/10.1089/ vbz.2009.0168

9. Li F, Meng JH, Dong C, Dai X, Yang YG, Zhou ZX. Design and application of a set of universal PCR primers for genotyping of hepatitis E virus [in Chinese]. Bing Du Xue Bao. 2009;25:9-16.

10. Smith DB, Simmonds P, Izopet J, Oliveira-Filho EF, Ulrich RG, Johne R, et al. Proposed reference sequences for hepatitis E virus subtypes. J Gen Virol. 2016;97:537-42. http://dx.doi.org/10.1099/ jgv.0.000393

Address for correspondence: Aiqiang Xu, Shandong Center for Disease Control and Prevention, 16992, Jingshi Road, Jinan, 250014, China; email: aqxuepi@163.com

\section{Introgressed Animal Schistosomes Schistosoma curassoni and S. bovis Naturally Infecting Humans}

\author{
Elsa Léger, Amadou Garba, Amina A. Hamidou, \\ Bonnie L. Webster, Tom Pennance, \\ David Rollinson, Joanne P. Webster
}

Author affiliations: Royal Veterinary College, University of London, London, UK (E. Léger, T. Pennance, J.P. Webster); RISEAL Niger, Niamey, Niger (A. Garba, A.A. Hamidou); Natural History Museum, London (B.L. Webster, D. Rollinson)

DOI: http://dx.doi.org/10.3201/eid2212.160644

To the Editor: Schistosomiasis, a disease caused by infection with parasitic worms (schistosomes), is a neglected tropical disease across many parts of the world. Numbers of infected livestock are unknown, but $>250$ million persons are infected; the greatest number of cases are in sub-Saharan Africa (1). Schistosome eggs are excreted through urine or feces, depending on the species, and hatch into miracidia upon contact with freshwater. Larvae are transmitted to the mammalian host indirectly through a molluscan intermediate host. Goals to eliminate schistosomiasis by 2020 in select countries in Africa have 